\title{
The Effectiveness of the Continuation Task on Second Language Learning of English Articles
}

\author{
Lin Jiang ${ }^{1}$ \\ ${ }^{1}$ Faculty of English Language \& Culture, Guangdong University of Foreign Studies, Guangzhou, China \\ Correspondence: Lin Jiang, Faculty of English Language \& Culture, Guangdong University of Foreign Studies, \\ Guangzhou, 510420, China. E-mail: jlin@gdufs.edu.cn
}

Received: September 14, 2015

doi:10.5539/elt.v8n11p79
Accepted: October 8, 2015 Online Published: October 9, 2015

URL: http://dx.doi.org/10.5539/elt.v8n11p79

\begin{abstract}
This article aims to uncover how alignment in the continuation task affects second language (L2) learning of English articles. Two classes of 47 Chinese students participated in the study which employed a pretest-treatment-posttest research design and lasted for a period of 20 weeks. One class received the continuation task treatment, during which learners first read a provided text and then continued it to make a complete story. The other class received the traditional topic-writing task treatment, during which learners were required to write a composition on a given topic. An error correction test and a picture description test were used to assess learners' L2 learning of English articles. Results showed that the continuation task was superior to the topic-writing task in facilitating L2 learning of articles, suggesting that the intimate coupling of production with comprehension in the continuation task triggers interaction between learners and the text, thus motivating learners to use the linguistic forms immediately available in the preceding text to make the content and language of their continuations in line with the text. This process can no doubt enhance the likelihood of L2 learning, especially in terms of article use.
\end{abstract}

Keywords: alignment, the continuation task, English articles, frequency, awareness

\section{Introduction}

Since Pickering and Garrod published their 2004 paper, "Toward a mechanistic psychology of dialogue", the role of alignment in successful communication has been of considerable interest to psycholinguists (Atkinson, Nishino, \& Churchill, 2007; Costa, Pickering, \& Sorace, 2008; Pickering \& Garrod, 2006; Wang \& Wang, 2014). Their fundamental claim is that successful communication is the result of interlocutors tending to produce and interpret expressions in the same ways that their partners have just done. In their terminology, the interlocutors' situation models become aligned. Moreover, Atkinson et al. (2007) argued for the crucial role of alignment in L2 acquisition and maintained that "human beings effect coordinated interaction, both with other human beings and environments, situations, tools, and affordances" (p. 169). This claim triggered the transfer of research focus from interpersonal alignment in dialogue to alignment between human beings and their social and physical environment in L2 research.

In particular, Wang and Wang (2014) reported empirical evidence that alignment did occur in other forms of L2 learning than dialogue, as a learner took part in a continuation task where writing was coupled with reading. Results showed that learners used more lexical items which occurred in the original story and committed significantly fewer errors in their continuations. So far, a few studies have touched on the issue of how L2 writing is affected by alignment in the continuation task (e.g., Jiang \& Chen, 2015; Xiao, 2013; Xue, 2013). However, research on whether alignment in this task can be further utilized to facilitate L2 learning remains quite rare in the literature. In fact, the usefulness of the continuation task as a valid tool for L2 learning worth further exploring (Wang \& Wang, 2014). For this, the present study conducted an experiment to exploit the extent to which alignment in the continuation task affects Chinese English-as-a-foreign-language (EFL) learners' acquisition of articles. 


\section{Alignment: From a Mechanistic Psychology to a Sociocognitive Process}

The second language acquisition (SLA) field in the past 20 years has experienced a paradigm shift; that is, the overwhelming cognitive orientation has gradually given away to approaches that give credit to social interaction. Alignment, a social cognitive process involving dynamic coordination and adaptation, has aroused considerable interest in the field of L2 research. The notion of alignment stems from Pickering and Garrod's (2004) study on first language (L1) use. According to them, what makes conversation so easy is the underlying interactive alignment mechanism, whereby interlocutors coordinate with each other in a dynamic and adaptive way during conversation. For example, concerning the spatial dimension, Schober (1993) reported that interlocutors tended to adopt the same reference frame as each other. If A said on the left meaning on A's left (an egocentric reference frame), then B would subsequently describe similar locations as on the right (also taking an egocentric reference frame rather than an allocentric reference frame).

Alignment of mental representations can happen at various levels. For example, at the syntactic level, Bock (1986) found that when a sentence such as The girl gave the boy a book was spoken or heard, the same structure was often used to describe a transfer event in a subsequent utterance such as Tom showed Mary a picture, instead of the alternate structure Tom showed a picture to Mary. At the lexical level, for example, Levelt and Kelter (1982) found that speakers tended to reply to "What time do you close?" or "At what time do you close?" with a congruent answer (e.g., "Five o'clock" or "At Five o'clock")(the repetition of "At"). In addition, alignment can take place at phonetic level (Pardo, Gibbons, Suppes, \& Krauss, 2012), pragmatic level (Roche, Dale, \& Caucci, 2012), and accent and speech rate (Giles, Coupland, \& Coupland, 1991). Interestingly, the non-verbal behavior can also become aligned, as for example when interlocutors come to mimic each other's posture (Shockley, Santana, \& Fowler, 2003), gestures (Holler \& Wilkin, 2011), and body movements (Chartrand \& Bargh, 1999). According to Pickering and Garrod (2004), these levels are interconnected so that aligned representation at one level would activate alignment at other levels, which can give rise to a coordinated behavior in dialogue.

Atkinson et al. (2007) approached alignment from a sociocognitive perspective. According to them, alignment "is the means by which human actors dynamically adapt to, flexibly depend on, integrate with, and construct the ever changing mind-body-world environments" (p. 171). Obviously, their point of view went beyond the scope of interpersonal alignment and emphasized adaptive alignment "between human beings and their social and physical environment" (p. 170). Nishino and Atkinson (2015) even argued that alignment underlied all forms of social behavior. For example, people unconsciously adjust their speed, proximity, and direction when walking together; people follow landmarks, lane marks, street signs, traffic signals, and other cars when driving cars; people employ turn-taking, repair strategies, intonation, gaze, head and body movements, gestures, and facial expressions to coordinate when talking with others.

This broadly-defined concept of alignment can not only explain how human beings survive and refine their abilities in the evolutionary process by adapting to the environment in general, but also how L2 learning takes place in particular. Atkinson et al. (2007) studied a scenario of a Japanese high school student Ako who studied the have you ever construction with the help of her aunt Tomo, an accomplished user of English. Through an in-depth analysis of the videotaped interaction, it was found that multiple forms of mind-body-world alignment took place in the process. For example, both participants aligned with each other in terms of gesture, eye gaze, bodily orientation, linguistic repetition, intonation and speech volume, and both displayed alignment with environmental affordances such as pens, worksheets, desks in an effort of meaning-making. Given that the co-occurrence of multidimensional alignment might produce a synergistic effect on L2 learning, Atkinson (2014) therefore argued that alignment through interaction with the sociocognitive environment is "a major facilitator of SLA" (p. 9). Overall, the sociocognitive approach to alignment has "opened up a new avenue to L2 research, whereby the role of interaction in L2 learning processes can be scrutinized in a more in-depth manner" (Wang \& Wang, 2014).

\section{The Continuation Task and L2 Learning}

L2 research on alignment from sociocognitive perspective is just beginning. Atkinson (2011) asserted that the approach was "so new and underdeveloped that it seem(ed) open to the full range of possibilities", and that "any account of its research methods must be emergent and prospective" (p. 162). In recent years, the continuation task becomes the most commonly used method in L2 research on alignment between human beings and their social environment. Different from the traditional reading-writing task, this task provides a learner a story with its ending removed. Learners should first read the provided text and then continue it to make a complete story. In 
so doing, learners have to align with the provided text both in language and content so as to make their writing cohere with it. Wang (2013) believed that the intimate coupling of production with comprehension in the continuation task can reinforce input/output coordination, create communicative needs, motivate mindreading, and enable learners to discern communicative intentions of the text writer, and, more importantly, it can bring about interaction and alignment between learners and the text. According to him, there are various ways of combining production with comprehension such as asking students to write reflections or summaries after reading a story, but such tasks may not compare favorably with the continuation task in terms of alignment intensity.

Wang and Wang (2014) was a typical L2 study on alignment in the continuation task. 48 Chinese EFL learners were provided with an English as well as a Chinese version of a story with their endings removed, and they were required to complete the story in English. Results showed that when participants continued the story following the reading of its English version, the words that appeared most frequently also appeared in the original text. However, when participants continued the story following the reading of its Chinese version, no such alignment effect was observed since they had no English input to align with. Moreover, participants committed significantly fewer errors following the reading of the English version in contrast to their performance in the Chinese-version task. Based on these results, they argued that the continuation task which intimately coupled reading with writing can entail alignment effect and this effect can significantly affect learners' L2 writing.

In addition, a series of empirical studies have been conducted to explore the variables that might affect the magnitude of alignment in the continuation task. Xue (2013) found that learners who wrote after reading an interesting story would align more and better with the original story than those who wrote after reading an uninteresting story. Yuan (2013) showed that learners following the explicit task instruction were more apt to produce the words, phrases and sentence structures of the provided text than those following the implicit task instruction. Xiao (2013) showed that learners exhibited a stronger alignment effect in the presence of the provided text as compared with the absence of the text. In Pang's (2014) study, learners' continuations after learner-learner interaction aligned more frequently with the preceding text in terms of words, phrases, and sentences than those without peer interaction.

Different from the above studies, Chen (2013) investigated what kinds of language abilities underlied learners' performance in the continuation task. Four forth-year English majors at a college in China were required to think aloud while writing a continuation to an interesting English story. Then these participants were interviewed about their evaluation of the task. It was showed that learners employed three kinds of language abilities in completing the task: grammatical knowledge, textual knowledge, and strategic competence in light of Bachman and Palmer's (2010) language ability model. Grammatical knowledge was reflected in learners' ability to ensure the accuracy of language use through aligning with the preceding text. Textual knowledge manifested itself in learners' ability to keep coherent. Strategic competence pertained to the use of alignment-based strategy to successfully and efficiently complete the task. She argued that these language abilities could facilitate L2 learning.

In sum, current L2 studies on the continuation task have laid too much emphasis on exploring whether alignment occurred and how it affected the accuracy of the continuation. However, making fewer errors in the continuation does not necessarily mean L2 learning has happened. In order to examine the effectiveness of the task in promoting L2 learning, fine-grained empirical studies should be conducted to directly examine its short-term and long-term learning effects. The present study attempts to address this issue by investigating the extent to which alignment in the continuation task facilitates L2 learning of English articles.

\section{English Articles in L2 Acquisition}

English articles are claimed to be among the most difficult grammatical forms for L2 learners to master (e.g., Bitchener, Young, \& Cameron, 2005; Butler, 2002; Ferris, 2002, 2006; Master, 1995). The learnability problem is probably due to the following two reasons. First, English articles remain obscure and non-salient in input, and misuse of articles rarely results in communication breakdown (Master, 2002). Therefore, according to Van Patten's Theory of Input Processing (Van Patten, 1996; 2002), learners' awareness is hard to be drawn to article forms. Given that conscious attention to linguistic forms is considered facilitative to or even a prerequisite for L2 learning (e.g., Schmidt, 2001), it's not hard to imagine why English articles pose a great difficulty for L2 learners. Second, some languages such as Chinese are generally acknowledged as a language with no functional equivalent of the English article system (Robertson, 2000). That is to say, for Chinese EFL learners to grasp the correct usage of articles, they have to get rid of the negative transfer from their mother tongue so as to bring 
about cognitive integration of syntactic, semantic, and pragmatic knowledge in L2 learning of articles.

In fact, current studies on L2 acquisition of English articles have laid too much emphasis on analyzing learners' errors but rather less on how to draw on some explicit intervention to facilitate learners' mastery of articles. As described earlier, the continuation task that provides input, motivates output, and more importantly, couples input with output might be an efficient tool for L2 learning. Thus, the present study will examine its effectiveness in facilitating L2 acquisition of English articles.

\section{The Study}

\subsection{Research Question}

In line with the above discussions, this study addresses the following research question, which has not yet been explored in the existing literature:

Can the continuation task facilitate Chinese EFL learners' acquisition of articles?

\subsection{Context}

This study was conducted in an Intermediate English Writing Course at a university in China. The course has a primary focus on narration and description, aiming at helping Chinese EFL learners to write either to entertain or to inform. In this writing course, the topic-writing task that requires students to write a composition on a given topic is the most often used method to encourage students to practice their English writing. The following is one of the topic-writing tasks suggested in the course.

Write a composition of at least 300 words to describe your own experiences of the change in your life due to the advent of a household applicance-Maybe a TV, or a computer, or something else.

The course is established specially for the freshmen of English major with an average class size of 26 students. Classes are offered in the second term of the first academic year, and each class lasts for 1 hour and 20 minutes, one class per week.

\subsection{Participants}

Forty-seven students from two intact classes of the Intermediate English Writing Course participated in this study. The two classes were taught by the same writing teacher and exposed to equal environments except for the treatment. Participants' ages varied from seventeen to twenty and all had learnt English for about eight years. They came from the same educational background (high school diploma) and were attending the same compulsory English courses (e.g., listening, reading, writing and speaking etc.) appointed by their faculty. In the study, one class was assigned to take the continuation task treatment (i.e. the continuation group, $\mathrm{N}=24$ ), while the other took the traditional topic-writing task treatment (i.e. the topic-writing group, $\mathrm{N}=23$ ). An English proficiency test, namely the Quick Placement Test (UCLES, 2001), was administrated to all participants before the experiment. T-test results showed no significant difference between the two groups, $t=.216, p>.05$, indicating that they were at the same English proficiency level.

\subsection{Target Structure}

Previous L2 studies on English articles exclusively focused on two functional uses of the article system, that is, the indefinite article $a / n$ for first mention and the definite article the for subsequent mention. In order to present a full picture of Chinese EFL learners' acquisition of the article system, eight functional uses were targeted in the present study as shown in Table 1. 
Table 1. Eight functional uses of the English article system

\begin{tabular}{|c|c|c|}
\hline \multirow{10}{*}{ Specificity } & Definite Article & Indefinite Article \\
\hline & $\begin{array}{l}\text { (1) The signals that a noun is definite, that it } \\
\text { refers to one particular member of a class. }\end{array}$ & $\begin{array}{l}\text { (5) a/n means "one" } \\
\text { e.g., a mile or two }\end{array}$ \\
\hline & e.g., The dog is in the corner. & \\
\hline & $\begin{array}{l}\text { (2) The is used afterwards, each time the noun is } \\
\text { mentioned. }\end{array}$ & $\begin{array}{l}\text { (6) } a / n \text { signals that the noun it modifies is } \\
\text { indefinite, that it refers to any member of }\end{array}$ \\
\hline & e.g., John bought a TV and a video recorder, but & a class. \\
\hline & he returned the video recorder. & $\begin{array}{l}\text { e.g., Leonard wants to marry a princess } \\
\text { who speaks five languages. }\end{array}$ \\
\hline & $\begin{array}{l}\text { (3) The signals that a noun is used as an } \\
\text { anaphor, that it refers to something talked later. }\end{array}$ & $\begin{array}{l}\text { (7) } a / n \text { is used to introduce a noun when } \\
\text { it is mentioned for the first time in a piece }\end{array}$ \\
\hline & e.g., The girls sitting over there are my cousins. & of writing. \\
\hline & $\begin{array}{l}\text { (4) The is used when what its noun refers to is } \\
\text { unique. }\end{array}$ & $\begin{array}{l}\text { e.g., An intruder has stolen a vase. The } \\
\text { intruder stole the vase from a locked case. }\end{array}$ \\
\hline & e.g., The White House & I he case was smasned open. \\
\hline \multirow{3}{*}{ Generic } & \multicolumn{2}{|c|}{ (8) Both $a / n$ and the can indicate that the countable noun is referring to the whole class. } \\
\hline & \multicolumn{2}{|l|}{ e.g., a. A lion is fierce. } \\
\hline & \multicolumn{2}{|l|}{ b. The lion is fierce. } \\
\hline
\end{tabular}

\subsection{Design}

The study employed a pretest-treatment-posttest research design (see Table 2). The entire study covered three testing sessions and six treatment sessions, and lasted for a period of 20 weeks with a gap of six weeks between the first posttest (i.e. Posttest 1) and the second posttest (i.e. Posttest 2) when the two groups took summer holidays. Pretest was administered in week 1 . The six treatment sessions took place from week 2 to 13 . Posttest 1 was conducted one week after the sixth treatment session. Six weeks later, that is, in week 20, participants took Posttest 2. During each testing session, two subtests were administered: an error correction test and a picture description test.

Table 2. Research design

\begin{tabular}{|c|c|c|c|c|}
\hline & Week 1 & Week 2-13 & Week 14 & Week 20 \\
\hline Group & Pretest & Treatment & Posttest 1 & Posttest 2 \\
\hline Continuation & $\begin{array}{l}\text { Error correction test } \\
\text { Picture description } \\
\text { test }\end{array}$ & $\begin{array}{l}\text { Continuation } \\
\text { task }\end{array}$ & $\begin{array}{l}\text { Error correction test } \\
\text { Picture description } \\
\text { test }\end{array}$ & $\begin{array}{l}\text { Error correction test } \\
\text { Picture description } \\
\text { test }\end{array}$ \\
\hline Topic-writing & $\begin{array}{l}\text { Error correction test } \\
\text { Picture description } \\
\text { test }\end{array}$ & $\begin{array}{l}\text { Topic-writing } \\
\text { task }\end{array}$ & $\begin{array}{l}\text { Error correction test } \\
\text { Picture description } \\
\text { test }\end{array}$ & $\begin{array}{l}\text { Error correction test } \\
\text { Picture description } \\
\text { test }\end{array}$ \\
\hline
\end{tabular}

\subsection{Instruments}

Two kinds of instruments were used in the experiment: treatment instruments for six treatment sessions, and testing instruments for three testing sessions.

\subsubsection{Treatment Instruments}

For the continuation group, treatment instruments included six short, interesting, and open-ended English stories, 
one for each session. They were The Unlocked Door, A Moving Story about Family, When the Car is Waiting, Happiness for Sale, Tell Mommy You Love Her, and The Lady or the Tiger. In each session, participants were required to write a continuation to one story during regular class time, and received teacher's feedback on their writing the following week.

For the topic-writing group, treatment instruments consisted of six writing topics without text input, for example, write a satirical story of at least 300 words about anything irrational in your life. Participants finished the writing in class and received teacher's feedback the next week.

\subsubsection{Testing Instruments}

According to Hughes (2000), the best way to test people's language ability is to get them to write. He also emphasized that considering learners' performance even on the same task was unlikely to be perfectly consistent, learners should be offered as many "fresh starts" as possible, and each task can represent a fresh start. Additionally, Luria (1958) from the perspective of dynamic assessment stated that development should not be only evaluated by learners' performance on immediate tasks but, more importantly, on their ability to utilize what they have learnt to new tasks. As a consequence, two tests were used to measure learners' L2 acquisition in this study: an error correction test and a picture description test. Both tests were different from the writing tasks (i.e. the topic-writing task and the continuation task) employed in the treatment and thus provided a measure of learners' ability to utilize what they learned in the treatment to new tasks.

\section{- $\quad$ Error Correction Test (20 minutes)}

The error correction test consisted of 32 items with one and only one error in each item. Learners were instructed to locate the errors and make corrections. Among the 32 items, 16 items involved the incorrect use of English articles with each functional use covering 2 items. The other 16 items were distracters involving the incorrect use of tense, plural, subject-verb agreement, or prepositions. The following example is taken from the test.

(1) * Tiger is a fearful animal.

Learners were assigned one point for each correct suppliance of an article in the 16 obligatory contexts. Distracters were not included in scoring, thus the total score for this test was 16 points. Learners' final scores were converted into percentages. The same testing materials were used for Pretest, Posttest 1, and Posttest 2, but the order of the items was randomly changed from one testing session to another.

\section{- $\quad$ Picture Description Test (50 minutes)}

The picture description test required participants to observe the drawing carefully, then write a composition of at least 300 words by imagination to tell what was happening, what had happened, or what would happen based on the picture. Pretest and Posttest 2 employed version A of the testing material while Posttest 1 used version B (see Figure 1). There was a span of about five months between Pretest and Posttest 2, so the memory effect could be eliminated. In addition, the two versions were quite similar in difficulty, and this might enhance reliability of the testing instruments.

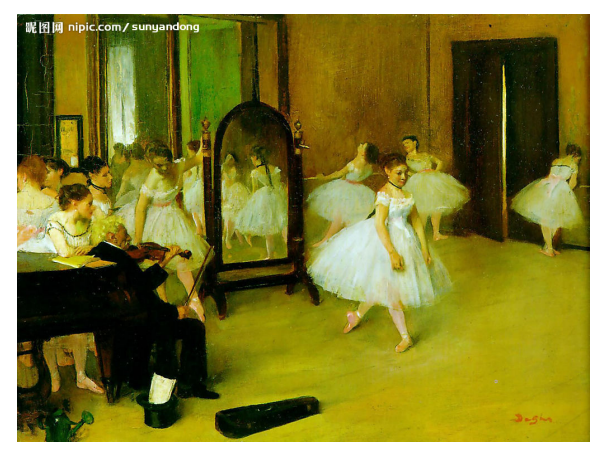

(A)

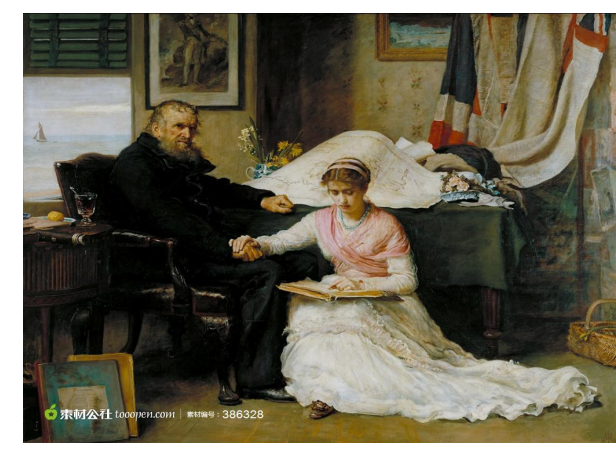

(B)

Figure 1. Pictures used in the picture description test

The Target-Like-Use formula (Pica, 1991) was employed to calculate accuracy of article use, as shown in Figure 
2. Specifically, all obligatory occasions for the eight functional uses of English articles were first identified and each occasion was examined to see whether the correct article had been supplied. Suppliance in non-obligatory contexts was also taken into account as the overuse of articles. The number of correct suppliance in obligatory contexts became the numerator of a ratio, and the denominator was the sum of the number of obligatory contexts for articles and the number of suppliance of articles in non-obligatory contexts.

\begin{tabular}{|l|}
\hline$n$ correct suppliance in obligatory contexts \\
\hline$n$ obligatory contexts $+n$ suppliance in non-obligatory contexts
\end{tabular}

Figure 2. The Target-Like-Use formula

Participants' writing in Pretest, Posttest 1, and Posttest 2 were evaluated by two Chinese learners of English who were postgraduate students majored in applied linguistics. Results of Pearson Correlation analysis indicated that the coefficients between the two raters were $.856, .771$, and .762 for Pretest, Posttest 1, and Posttest 2, respectively. Cumming, Kantor, Baba, Erdosy, Eoanzoui, \& James (2005) pointed out that an inter-rater reliability score of .76 on error coding was adequate. Thus, the scorings in this study had a high level of inter-rater reliability and the data obtained are reliable for subsequent analysis.

\section{Results}

Table 3 presents the descriptive statistics for the error correction test and the picture description test over the three testing periods: Pretest, Posttest 1, and Posttest 2. Results on each test are shown in what follows.

Table 3. Group means and standard deviations (SD) for mean scores of the tests

\begin{tabular}{|c|c|c|c|c|c|c|c|}
\hline \multirow{2}{*}{ Test } & \multirow{2}{*}{ Group } & \multicolumn{2}{|c|}{ Pretest } & \multicolumn{2}{|c|}{ Posttest 1} & \multicolumn{2}{|c|}{ Posttest 2} \\
\hline & & Mean & SD & Mean & SD & Mean & SD \\
\hline \multirow{2}{*}{$\begin{array}{l}\text { Error } \\
\text { correction } \\
\text { test }\end{array}$} & Topic-writing & 0.34 & 0.04 & 0.36 & 0.04 & 0.36 & 0.03 \\
\hline & Continuation & 0.36 & 0.05 & 0.44 & 0.05 & 0.45 & 0.04 \\
\hline \multirow{2}{*}{$\begin{array}{l}\text { Picture } \\
\text { description } \\
\text { test }\end{array}$} & Topic-writing & 0.50 & 0.07 & 0.55 & 0.05 & 0.56 & 0.04 \\
\hline & Continuation & 0.49 & 0.06 & 0.63 & 0.05 & 0.65 & 0.03 \\
\hline
\end{tabular}

\subsection{Error Correction Test}

Descriptive statistics for the error correction test are illustrated in Figure 3. According to results of one-way repeated measures ANOVAs, both the topic-writing group and the continuation group showed significant longitudinal gains: $F=3.599, p<.05, F=18.900, p<.001$, respectively. For the topic-writing group, the gains observed between Pretest and Posttest 1 as well as between Pretest and Posttest 2 were significant (see Table 4). For the continuation group, the gains observed between Pretest and Posttest 1, between Pretest and Posttest 2, as well as between Posttest 1 and Posttest 2 were all significant (see Table 4).

Additionally, independent samples t-test showed that there was no significant difference between the two groups in Pretest, $t=-1.017, p>.05$. However, significant differences were reported in Posttest 1 and Posttest 2, $t=-6.015$, $p<.001, t=-8.715, p<.001$, respectively, with the continuation group's scores significantly higher than those of the topic-writing group. 


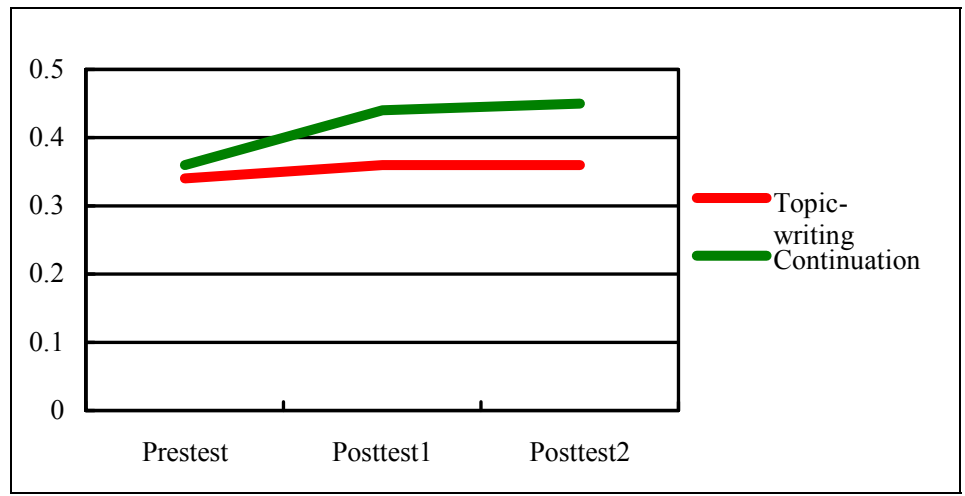

Figure 3. Group means on error correction test

\subsection{Picture Description Test}

Descriptive statistics for the picture description test are illustrated in Figure 4. According to results of one-way repeated measures ANOVAs, both the topic-writing group and the continuation group showed significant longitudinal gains: $F=19.383, p<.001, F=121.784, p<.001$, respectively. For the topic-writing group, the gains observed between Pretest and Posttest 1, between Pretest and Posttest 2, as well as between Posttest 1 and Posttest 2 were all significant (see Table 4). For the continuation group, the gains observed between Pretest and Posttest 1, between Pretest and Posttest 2, as well as between Posttest 1 and Posttest 2 were all significant (see Table 4).

Additionally, independent samples t-test showed that there was no significant difference between the two groups in Pretest, $t=.649, p>.05$. However, significant differences were reported in Posttest 1 and Posttest 2, $t=-5.829$, $p<.001, t=-7.533, p<.001$, respectively, with the continuation group's scores significantly higher than those of the topic-writing group.

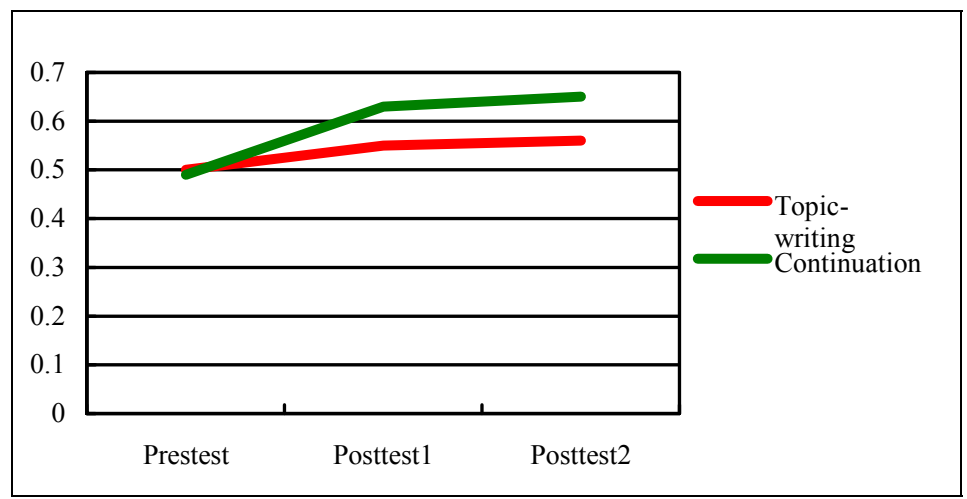

Figure 4. Group means on picture description test 
Table 4. Results of one-way repeated measures ANOVAs

\begin{tabular}{lll}
\hline Group & Error correction test & Picture description test \\
\hline \multirow{3}{*}{ Topic-writing } & *Pretest $<$ posttest 1 & $*$ pretest $<$ posttest 1 \\
& $*$ Pretest $<$ posttest2 & $*$ pretest $<$ posttest 2 \\
& posttest $1>$ posttest2 & $*$ posttest $1<$ posttest2 \\
\cline { 2 - 3 } Continuation & $* * *$ pretest $<$ posttest 1 & $* * *$ pretest $<$ posttest 1 \\
& $* * *$ pretest $<$ posttest2 & $* * *$ pretest $<$ posttest2 \\
& $*$ posttest $1<$ posttest2 & $*$ posttest $1<$ posttest2 \\
\hline
\end{tabular}

Note: ${ }^{*} \mathrm{p}<.05 ; * * \mathrm{p}<.01 ; * * * \mathrm{p}<.001$

\subsection{Summary of the Results}

In sum, results of the present study are summarized as follows: in both the error correction test and the picture description test, the continuation group performed much better than the topic-writing group in Posttest 1 and posttest 2 , suggesting that the continuation task was superior to the topic-writing task in facilitating Chinese EFL learners' acquisition of articles.

\section{Discussion}

To sum up, this study has found that the continuation task was superior to the topic-writing task on Chinese EFL learners' acquisition of articles in both the short- and the long-term. This finding on the one hand broadens the scope of the current research on alignment by confirming once again that alignment does occur in forms other than interpersonal interaction, on which alignment studies have focused almost exclusively in so far. On the other hand, it serves as further evidence that alignment originating from the continuation task can facilitate L2 learning, especially with regard to Chinese EFL learners' acquisition of articles.

In the study, the continuation group participated in six sessions of the continuation task treatment. Each time when learners were required to continue a story, they needed, first and foremost, to wrestle with the text for comprehension that required construction of a situation model. This construction, which was based on an incomplete story, not only motivated learners to generate new ideas for writing but also do much to make the content and language of their continuations in line with the text. In so doing, learners had to draw on the linguistic expressions in the text for their continuations. Furthermore, upon encountering difficulty in language use, learners would access to constructions immediately available in the preceding text. The above situations can no doubt increase the likelihood of L2 learning. In the following I explain how the continuation task benefits L2 acquisition of English articles in light of the usage-based theory of language acquisition.

First, the continuation task can raise learners' awareness on article forms. Awareness is a prerequisite condition of language learning (Schmidt, 2001). The sociocultural theory (Vygotsky, 1978) believed that the awareness of external sensation would subject learners into internal voluntary control, in other words, they learned the "sensation from within" (Zinchenko, 2002). In the continuation task learners wrestled with the text for making continuation, during which learners' awareness was drawn to the gap between what they could produce and what they needed to produce, as well as between what they produced and what native speakers produced in terms of articles. Such a cognitive comparison then stimulated learners to intentionally imitate and internalize the input language, triggering a modification of their current interlanguage grammar.

Besides, the continuation task coupling input with output can assist learners to bridge the gap between their interlanguage and the target language. In the study the provided texts in the treatment included a variety of article uses. According to the usage-based theory of language acquisition, frequency of exposure has a determinant impact on the emergence of linguistic structures (Ellis, 2002). Specifically, increased token frequency promoted the entrenchment of article construction, while increased type frequency strengthened the generality and abstraction of article construction. Altogether, every time learners comprehend an article, it reinforces their mental representations, which in turn facilitates the activation of this expression in language use (Diessel, 2004). More strikingly, learners not only comprehend but also produce in the continuation task; they extend what they acquire from the input to a new context. This was evidenced in a number of L2 studies on the 
continuation task. For example, Wang and Wang (2014) found that most of the unusually frequent expressions and structures in the continuations were those that appeared in the original stories. According to usage-based theory of language acquisition, knowledge of a language is based on knowledge of actual usage and generalizations made over usage events (Goldberg, 2006; Langacker, 1987, 1991; Tomasello, 2003). The typical route of emergence of constructions is from formula, through low-scope pattern, to construction. In the study when Chinese EFL learners used English articles as a formula or as a limited-scope pattern, the continuation task might help them produce that form with new lexical items, which could facilitate the acquisition of more abstract representations.

However, the topic-writing task presents a somewhat different picture. When taking part in this task, no input was available for learners to align with. In such a case, their L1-based knowledge was activated. Consequently, linguistic errors in articles might arise, and the complex use of articles would be avoided in their writing, which may in turn impact their L2 learning. Such an effect is not only significant but also can be sustained over time. Moreover, in the absence of a text, learners would not "notice the gap", hence they would pay less attention on language forms while more attention on content and ideas of their writing. It is generally assumed that learners need to be drawn to linguistic forms so as to be able to make progress in their well-formed L2 use (Ellis, 2005; Norris \& Ortega, 2003). Therefore, you would not find it surprising when the continuation group achieved a better control of producing grammatically correct articles in the posttests compared with the topic-writing group.

It should be noted that although the continuation task is superior to the topic-writing task in L2 learning, the topic-writing group did make significant longitudinal gains in terms of their article knowledge. The implication we can get from this finding is that output enjoys great significance in the process of language acquisition. According to the Output Hypothesis (Swain, 2005), output pushes learners to process language more deeply and with more mental effort than is necessary during listening and reading. Therefore, the foreign language classes should increase the chance of learners' output and promote their L2 development.

\section{Conclusion}

Since Pickering and Garrod (2004), alignment in language use and learning has aroused considerable interest in the field of psycholinguistics and L2 research. The current study took the research one step further, investigating how alignment in the continuation task which couples comprehension with production affected Chinese EFL learners' acquisition of articles. Results showed that the continuation task was superior to the traditional topic-writing task in facilitating L2 learning of articles, suggesting that the intimate coupling of production with comprehension in the task triggered interaction between learners and the text, thus motivating learners to use the linguistic forms immediately available in the preceding text to make the content and language of their continuations in line with the text. This process can no doubt enhance the likelihood of L2 learning. One implication from the current study is that the continuation task is a useful tool for L2 learning. More fine-graded studies are needed to use this task as a means for tapping L2 learning process and its uses in foreign language classes are worth further exploring.

\section{Acknowledgements}

This research was supported by a grant from the China National Social Science Foundation (14CYY018).

\section{References}

Atkinson, D. (2011). A sociocognitive approach to second language acquisition: How mind, body and world work together in learning additional languages. In D. Atkinson (Ed.), Alternative Approaches to Second Language Acquisition (pp. 143-166). Oxford: Routledge.

Atkinson, D. (2014). Language learning in mind-body-world: A sociocognitive approach to second language acquisition. Language Teaching, 47, 467-483.

Atkinson, D., Nishino, T., Churchill, E., \& Okada, H. (2007). Alignment and interaction in a sociocognitive approach to second language acquisition. The Modern Language Journal, 91, 169-188. http://dx.doi.org/10.1111/j.1540-4781.2007.00539.x

Bachman, L., \& Palmer, A. S. (2010). Language assessment in practice. Oxford: Oxford University Press.

Bitchener, J., Young, S., \& Cameron, D. (2005). The effect of different types of corrective feedback on ESL student writing. Journal of Second Language Writing, 14, 191-205. http://dx.doi.org/10.1016/j.jslw.2005.08.001 
Bock, J. K. (1986). Syntactic persistence in language production. Cognitive Psychology, 18, 355-87. http://dx.doi.org/10.1016/0010-0285(86)90004-6

Butler, Y. G. (2002). Second language learners' theories on the use of English articles: An analysis of the metalinguistic knowledge used by Japanese students in acquiring the English article system. Studies in Second Language Acquisition, 24, 451-80. http://dx.doi.org/10.1017/S0272263102003042

Chartrand, T. L., \& Bargh, J. A. (1999). The chameleon effect: The perception-behavior link and social interaction. Journal of personality and social psychology, 76, 893-910. http://dx.doi.org/10.1037/0022-3514.76.6.893

Chen, J. (2013). What language abilities underlie the performance of continuation task? Unpublished MA thesis, Guangdong University of Foreign Studies.

Costa, A., Pickering, M. J., \& Sorace, A. (2008). Alignment in second language dialogue. Language and Cognitive Processes, 23, 528-556. http://dx.doi.org/10.1080/01690960801920545

Cumming, A., Kantor, R., Baba, K., Erdosy, U., Eoanzoui, K., \& James, M. (2005). Differences in writing discourse in independent and integrated prototype tasks for next generation TOEFL. Assessing Writing, 10, $5-43$.

Diessel, H. (2004). The acquisition of complex sentences. Cambridge: Cambridge University Press.

Ellis, N. (2005). At the interface: Dynamic interactions of explicit and implicit language knowledge. Studies in Second Language Acquisition, 27, 305-352. http://dx.doi.org/10.1017/S027226310505014X

Ellis, R. (2002). Does form-focused instruction affect the acquisition of implicit knowledge? A review of the research. Studies in Second Language Acquisition, 24, 223-236. http://dx.doi.org/10.1017/S0272263102002073

Ferris, D. R. (2002). Treatment of error in second language student writing. Michigan: The University of Michigan Press.

Ferris, D. R. (2006). Does error feedback help student writers? New evidence on the short- and long-term effects of written error correction. In K. Hyland, \& F. Hyland (Eds.), Perspectives on Response (pp. 81-104). New York: Cambridge University Press.

Giles, H., Coupland, N., \& Coupland, J. (1991). Accommodation theory: Communication, context, and consequence. In H. Giles, J. Coupland, \& N. Coupland (Eds.), Contexts of Accommodation: Developments in Applied Sociolinguistics (pp. 1-68). Cambridge, UK: Cambridge University Press.

Goldberg, A. E. (2006). Constructions at work: the nature of generalization in language. Oxford: Oxford University Press.

Holler, J., \& Wilkin, K. (2011). Co-speech gesture mimicry in the process of collaborative referring during face-to-face dialogue. Journal of Nonverbal Behavior, 35, 133-153. http://dx.doi.org/10.1007/s10919-011-0105-6

Hughes, A. (2000). Testing for language teachers. Beijing, China: Foreign Language Teaching and Research Press.

Jiang, L., \& Chen, J. (2015). The continuation task: Effects on written accuracy, complexity and fluency. Modern Foreign Languages, 38, 366-375.

Langacker, R. W. (1987). Foundations of cognitive grammar: Vol. 1. theoretical prerequisites. Stanford, CA: Stanford University Press.

Langacker, R. W. (1991). Foundations of cognitive grammar Vol. II: Descriptive application. Stanford: Stanford University Press.

Levelt, W. J., \& Kelter, S. (1982). Surface form and memory in question answering. Cognitive Psychology, 14, 78-106. http://dx.doi.org/10.1016/0010-0285(82)90005-6

Luria, A. R. (1958). Dynamic approach to the mental development of the abnormal child. Journal of Intellectual Disability Research, 2, 37-52. http://dx.doi.org/10.1111/j.1365-2788.1958.tb00384.x

Master, P. (1995). Consciousness raising and article pedagogy. In D. Belcher, \& G. Braine (Eds.), Academic 
Writing in a Second Language: Essays on Research and Pedagogy (pp. 183-204). Norwood, NJ: Ablex Publishing Corporation.

Master, P. (2002). Information structure and English article pedagogy. System, 30, 331-348. http://dx.doi.org/10.1016/S0346-251X(02)00018-0

Nishino, T., \& Atkinson, D. (2015). Second language writing as a sociocognitive alignment. Journal of Second Language Writing, 27, 37-54. http://dx.doi.org/10.1016/j.jslw.2014.11.002

Norris, J. M., \& Ortega, L. (2003). Defining and measuring SLA. In C. G. Doughty, \& M. H. Long (Eds.), Handbook of Second Language Acquisition (pp. 717-761). Oxford: Blackwell Publisher.

Pang, Y. (2014). The effect of peer interaction on alignment in a continuation task. Unpublished MA thesis, Guangdong University of Foreign Studies.

Pardo, J. S., Gibbons, R., Suppes, A., \& Krauss, R. M. (2012). Phonetic convergence in college roommate. Journal of Phonetics, 40, 190-197. http://dx.doi.org/10.1016/j.wocn.2011.10.001

Pica, T. (1991). Foreign language classrooms: Making them research-ready and researchable. In B. Freed (Ed.), Foreign Language Acquisition Research and the Classroom (pp. 393-412). Lexington, MA: D.C. Heath.

Pickering, M. J., \& Garrod, S. (2004). Toward a mechanistic psychology of dialogue. Behavioral and Brain Sciences, 27, 169-26. http://dx.doi.org/10.1017/S0140525X04000056

Pickering, M. J., \& Garrod, S. (2006). Alignment as the basis for successful communication. Research on Language and Computation, 4, 203-28. http://dx.doi.org/10.1007/s11168-006-9004-0

Robertson, D. (2000). Variability in the use of the English article system by Chinese learners of English. Second Language Research, 16, 135-172. http://dx.doi.org/10.1191/026765800672262975

Roche, J. M., Dale, R., \& Caucci, G. M. (2012). Doubling up on double meanings: Pragmatic alignment. Language and Cognitive Processes, 27, 1-24. http://dx.doi.org/10.1080/01690965.2010.509929

Schmidt, R. (2001). Attention. In P. Robinson (Ed.), Cognition and Second Language Instruction (pp. 3-32). New York: Cambridge University Press.

Schober, M. (1993). Spatial perspective-taking in conversation. Cognition, 47, 1-24. http://dx.doi.org/10.1016/0010-0277(93)90060-9

Shockley, K., Santana, M., \& Fowler, C. A. (2003). Mutual interpersonal postural constraints are involved in cooperative conversation. Journal of Experimental Psychology: Human Perception and Performance, 29, 326-332. http://dx.doi.org/10.1037/0096-1523.29.2.326

Swain, M. (2005). The output hypothesis: Theory and research. In E. Hinkel (Ed.), Handbook of Research in Second Language Teaching and Learning (pp. 471-484). New Jersey: Lawrence Erlbaum Associates.

Tomasello, M. (2003). Constructing a language. Cambridge, MA: Harvard University Press.

Van Patten, B. (1996). Input processing and grammar instruction in second language acquisition. Norwood, NJ: Ablex.

Van Patten, B. (2002). Processing instruction: An update. Language Learning, 52, 755-803.

Vygotsky, L. S. (1978). Mind and society: The development of higher mental processes. Cambridge, MA: Harvard University.

Wang, C. M. (2013). What kinds of exercises facilitate L2 learning? Contemporary Foreign Languages Studies, 2, 28-31.

Wang, C. M., \& Wang, M. (2014). Effect of alignment on L2 written production. Applied Linguistics (online advanced access). http://dx.doi.org/10.1093/applin/amt051

Xiao, T. (2013). The effect of alignment on L2 writing accuracy. Unpublished MA thesis, Guangdong University of Foreign Studies.

Xue, H. (2013). Interest-related alignment in L2 story continuation. Unpublished MA thesis, Guangdong University of Foreign Studies.

Yuan, D. (2013). The effect of task instructions on L2 writing from the perspective of alignment. Unpublished 
MA thesis, Guangdong University of Foreign Studies.

Zinchenko, V. P. (2002). From classical to organic psychology: In commemoration of the centennial of Lev Vygotsky's birth. In D. Robbins, \& A. Stetsenko (Eds.), Voices within Vygotsky's Non-classical Psychology (pp. 3-26). New York: Nova Science Publisher.

\section{Copyrights}

Copyright for this article is retained by the author(s), with first publication rights granted to the journal.

This is an open-access article distributed under the terms and conditions of the Creative Commons Attribution license (http://creativecommons.org/licenses/by/3.0/). 